\title{
Gestão de redes: a estratégia de regionalização da política de saúde
}

\author{
Network management: the strategy of \\ regionalizing healthcare policy
}

\author{
Luciano A. Prates Junqueira \\ Professor titular da Faculdade de Economia, Administração, Contabilidade e Atuária; coordenador \\ do Programa de Estudos Pós-graduados em Administração e do Núcleo de Estudos Avançados do \\ Terceiro Setor (Neats)/Pontifícia Universidade Católica de São Paulo \\ junq@pucsp.br \\ Fabíola Dapuzzo \\ Mestranda do Programa de Estudos Pós-graduados em Administração; membro do Neats/ \\ Pontifícia Universidade Católica de São Paulo \\ fabiola@vetorial.net
}

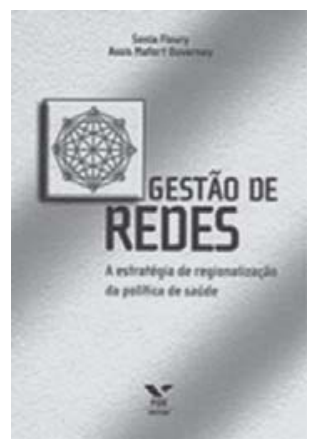

FLEURY, Sonia; OUVERNEY, Assis Mafort. Gestão de redes: a estratégia de regionalização da política de saúde. Rio de Janeiro: Editora FGV. 2007. 204p.

\begin{abstract}
A análise de redes sociais, em sua amplitude e multidisciplinaridade, trouxe o cruzamento de duas tradições distintas: de um lado, a dos cientistas sociais atuantes em uma linha mais qualitativa, que busca conceituar e entender, pela reflexão crítica sobre os fatos sociais, o que é rede social, quais são seus atributos relevantes e como eles evoluem; de outro, a dos que buscam construir modelos matemáticos cunhados em ferramental desenvolvido para a ciência física e química. Os primeiros lidam com o ambiente extremamente complexo; os segundos também lidam com a complexidade, mas criando modelos representativos que não apenas descrevem como também preveem a evolução das redes sociais, delineando técnicas e modelos para sua representação. Entretanto uma abordagem não substitui a outra; elas se complementam, pois a representação gráfica pode gerar novos insights e novas reflexões sobre as redes.

É no contexto da primeira dimensão que situamos o livro de Sonia Fleury e Assis Ouverney, Gestão de redes: a estratégia de regio-
\end{abstract} nalização da política de saúde. Os autores analisam, sob diversos pontos de vista, as redes na gestão das políticas públicas e em especial da saúde. Trazem para o debate de redes sociais no âmbito do setor público uma importante contribuição. Identificam os fatores que impulsionaram a emergência das redes de gestão e seu entendimento nas diversas áreas do conhecimento. O conceito de redes sociais, apesar de não ser novo, ganha relevância como meio de tornar mais democrática e descentralizada a gestão das políticas públicas.

O conceito de redes sociais surge na década de 1930, baseado na sociometria e para descrever e analisar a estrutura interpessoal presente no comportamento de pequenos grupos. Na década de 1960 são desenvolvidas modelagens matriciais de papéis sociais para mapear os padrões homogêneos das relações sociais. 
O surgimento das redes como modo de suprir a incapacidade de os governos darem conta da complexidade dos problemas sociais cria novas formas de coordenação para atender às demandas da população. Apesar de sua importância na gestão pública, elas possuem limitações para cumprir certas funções públicas de caráter estatal, como por exemplo garantir e regular os direitos sociais.

A proliferação das redes de gestão pública ocorreu em virtude das transformações nas relações entre Estado e sociedade. Nos países latino-americanos esse processo foi favorecido pela democratização, que ocasionou a criação de organizações sociais para defesa dos direitos sociais e para gestão das políticas públicas. A descentralização faz emergir uma nova modalidade de coordenação e gestão pública, em consequência do deslocamento da esfera de poder do Estado para a sociedade. Nesse processo as redes sociais assumem um papel privilegiado.

A rede tem como elemento estrutural básico o ator, uma unidade discreta que representa uma pessoa ou um conjunto agrupado em uma unidade social, como uma empresa ou associação, que possui atributos específicos e identificáveis. Os diversos atores que compõem a rede são, em geral, caracterizados como 'nós'. O conceito de rede como um conjunto de 'nós' conectados tem como pressuposto as relações sociais, a interação entre as unidades. Tal concepção permite visualizar a rede social como um conjunto de relacionamentos, uma malha, um tecido social que possui relações relativamente estáveis e de natureza não hierárquica e independente. A constituição da rede se faz mediante o compartilhamento, pelos atores que a compõem, de interesses e objetivos comuns definidos coletivamente.

A concepção de rede não é única, e o debate a seu respeito é exposto pelos autores com base em análise da literatura nacional e internacional. Eles apontam os elementos nucleares desse processo de rede social, que constituem sua razão de ser, como relações sociais e interação. Contudo a horizontalidade e a interdependência também fazem parte desse conceito de rede. $\mathrm{E}$ a interdependência é colocada como novo paradigma na gestão pública e considerada meio de institucionalização das redes. É apontada como um dos fatores que distinguem a rede de outros formatos de gestão, como as parcerias e a contratação. Essa diferença se deve à diversidade de atores, governamentais e não governamentais. A interdependência como elemento nuclear na discussão das redes é retomada pelos autores e considerada fundamental para a coordenação e a execução do planejamento. Mesmo que a interdependência não justifique o processo de institucionalização da rede, ela garante que os objetivos comuns e compartilhados sejam alcançados, uma vez que envolve uma multiplicidade de atores.

A contribuição de Fleury e Ouverney para o entendimento do processo de institucionalização das redes a partir da perspectiva da interdependência se revela na criação de uma tipologia construída a partir das relações da coordenação interorganizacional. Além de exemplificar os elementos de interdependência das redes pela institucionalização, os autores buscam compreender como as bases de suporte institucionais se articulam dentro da rede. Essas bases fornecem uma estrutura que possibilita a articulação e integração dos conjuntos de recursos envolvidos na rede, assim como o desenvolvimento de estratégias de sustentabilidade política no âmbito interno e externo. A existência da rede depende de uma realidade múltipla e complexa, em que o reconhecimento do outro e a definição de objetivos 
comuns para a construção de um tecido social podem tornar a gestão pública mais eficaz e eficiente.

A análise da implementação e do desenvolvimento do Sistema Único de Saúde (SUS) é um dos objetivos dessa obra feita a partir do olhar da rede, que possui diversas aplicações na área da saúde. Com a Constituição de 1988, o conceito de rede amplia seus significados, em decorrência da criação de novos vínculos e relações intergovernamentais na gestão da política de saúde. A incorporação das redes no funcionamento do SUS foi primordial para a melhoria do seu desempenho, com estratégias de regionalização, territorialização e planejamento integrado. Com o SUS criaram-se novas instâncias de poder articuladas e integradas, fazendo com que o processo de regionalização permitisse a construção de padrões de interdependência entre os três níveis de governo, garantindo o acesso universal e equitativo à saúde. A territorialização aprofunda a interdependência construída com a regionalização e delimita a interação entre atores, organização e recursos, fixando linhas e vínculos de estruturação no nível local.

O processo de planejamento integrado que surge com a territorialização não consegue gerar elementos dinâmicos, capazes de colocar em prática os princípios da universalidade, equidade e integralidade preconizados pelo SUS. Mas é mediante esse planejamento integrado de funções gerenciais como controle, programação, organização, monitoramento, entre outras, que os recursos são utilizados de forma mais eficiente. A partir da tipologia da interdependência das redes analisa-se o padrão de governança da estratégia de regionalização do SUS, com a edição da Norma Operacional de Assistência à Saúde (Noas).

As abordagens de rede e a análise da política de saúde apresentadas nessa obra certamente contribuirão para atualizar o debate nas ciências sociais, tanto da gestão pública de rede como do entendimento dos impasses da gestão da rede no SUS. A obra preenche uma lacuna, pois dá acesso a uma bibliografia ampla de redes sociais e cria uma tipologia de redes para análise da gestão das políticas públicas.

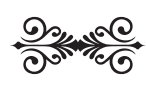

